\title{
Case 22-2019: A 65-Year-Old Woman with Myopathy.
}

Marinos C. Dalakas

Thomas Jefferson University

Follow this and additional works at: https://jdc.jefferson.edu/neurologyfp

Part of the Neurology Commons

Let us know how access to this document benefits you

\section{Recommended Citation}

Dalakas, Marinos C., "Case 22-2019: A 65-Year-Old Woman with Myopathy." (2019). Department of Neurology Faculty Papers. Paper 204.

https://jdc.jefferson.edu/neurologyfp/204

This Article is brought to you for free and open access by the Jefferson Digital Commons. The Jefferson Digital Commons is a service of Thomas Jefferson University's Center for Teaching and Learning (CTL). The Commons is a showcase for Jefferson books and journals, peer-reviewed scholarly publications, unique historical collections from the University archives, and teaching tools. The Jefferson Digital Commons allows researchers and interested readers anywhere in the world to learn about and keep up to date with Jefferson scholarship. This article has been accepted for inclusion in Department of Neurology Faculty Papers by an authorized administrator of the Jefferson Digital Commons. For more information, please contact: JeffersonDigitalCommons@jefferson.edu. 
2. Pareek $M$, Vaduganathan $M$, Biering-S申rensen $T$, et al. Pulse pressure, cardiovascular events, and intensive blood-pressure lowering in the Systolic Blood Pressure Intervention Trial (SPRINT). Am J Med 2019;132:733-9.

3. Vidal-Petiot E, Greenlaw N, Ford I, et al. Relationships between components of blood pressure and cardiovascular events in patients with stable coronary artery disease and hypertension. Hypertension 2018;71:168-76.
4. Bhatt DL. Troponin and the J-curve of diastolic blood pressure: when lower is not better. J Am Coll Cardiol 2016;68:1723-6. 5. Vidal-Petiot E, Ford I, Greenlaw N, et al. Cardiovascular event rates and mortality according to achieved systolic and diastolic blood pressure in patients with stable coronary artery disease: an international cohort study. Lancet 2016;388:214252.

DOI: 10.1056/NEJMc1911059

\section{Case 22-2019: A 65-Year-Old Woman with Myopathy}

TO THE EDITOR: The case reported by Freeman et al. (July 18 issue) ${ }^{1}$ contains conclusions that may perpetuate misconceptions. The patient had acute rhabdomyolysis and necrotizing autoimmune myositis, but the connection with statins is unlikely.

In this patient, myopathy started 2 weeks after coryza and cough; this suggests a preceding viral infection, which is a more likely trigger of necrotizing autoimmune myositis ${ }^{2}$ than atorvastatin, which had been initiated 6 months previously. Statins can rarely lead to acute myotoxicity, but the contention that they induce anti-HMGCR (3-hydroxy-3-methylglutaryl coenzyme A reductase)-mediated autoimmunity is unsubstantiated and disputed. ${ }^{3}$ HMGCR is normally expressed in regenerating rather than necrotic fibers, and there is no evidence that it induces muscle-fiber necrosis or triggers autoimmunity, especially since HMGCR is a ubiquitous cytoplasmic antigen that is not accessible to antiHMGCR antibodies. ${ }^{4}$ HMGCR is expressed in normal myotubes, but anti-HMGCR IgG does not induce myotubular necrosis ${ }^{5}$ and does not explain pathogenicity. ${ }^{4}$ Most important, antiHMGCR autoantibodies are not statin-specific because they are most frequently seen in patients with paraneoplastic, viral, or other forms of necrotizing autoimmune myositis who have not received statins. ${ }^{6}$

In the few patients in whom necrotizing autoimmune myositis does develop after receipt of statins for years, the association is more of a chance phenomenon, considering that necrotizing autoimmune myositis is now the most common inflammatory myopathy $y^{2,4}$ and that $25 \%$ of Americans older than 40 years of age take statins. The authors' conclusions could deprive the patient, as well as others with a similar presentation, of a helpful drug.

\author{
Marinos C. Dalakas, M.D. \\ Thomas Jefferson University \\ Philadelphia, PA \\ marinos.dalakas@jefferson.edu
}

No potential conflict of interest relevant to this letter was reported.

1. Case Records of the Massachusetts General Hospital (Case 222019). N Engl J Med 2019;381:275-83.

2. Dalakas MC. Inflammatory muscle diseases. $N$ Engl J Med 2015;372:1734-47.

3. Allenbach Y, Arouche-Delaperche L, Preusse C, et al. Necrosis in anti-SRP ${ }^{+}$and anti-HMGCR ${ }^{+}$myopathies: role of autoantibodies and complement. Neurology 2018;90(6):e507-e517.

4. Dalakas MC. Myositis: are autoantibodies pathogenic in necrotizing myopathy? Nat Rev Rheumatol 2018;14:251-2.

5. Arouche-Delaperche L, Allenbach Y, Amelin D, et al. Pathogenic role of anti-signal recognition protein and anti-3-hydroxy3-methylglutaryl-CoA reductase antibodies in necrotizing myopathies: myofiber atrophy and impairment of muscle regeneration in necrotizing autoimmune myopathies. Ann Neurol 2017;81:538-48.

6. Watanabe Y, Uruha A, Suzuki S, et al. Clinical features and prognosis in anti-SRP and anti-HMGCR necrotising myopathy. J Neurol Neurosurg Psychiatry 2016;87:1038-44.

DOI: 10.1056/NEJMc1911058

TO THE EDITOR: We would like to expand on the discussion by Freeman et al. on statin-associated autoimmune myopathy with autoantibodies against HMGCR in a patient who had been prescribed a statin medication. First, we would note that this disease may also be associated with a dietary source of statins, such as red yeast rice or oyster mushrooms. ${ }^{1}$ Second, since at least $25 \%$ of patients with anti-HMGCR-associated autoimmune myopathy have no known exposure to statins, ${ }^{2}$ testing for anti-HMGCR autoantibodies may be considered in other patients with myopathy. This includes adults and children with clinical presentations that are consistent with genetic muscle disease but no known genetic defect; some of these patients have anti-HMGCR-associated autoimmune myopathy that responds to treatment. ${ }^{3}$ Third, reinitiation of statins is con- 
traindicated in patients with statin-associated autoimmune myopathy. However, the use of proprotein convertase subtilisin-kexin type 9 (PCSK9) inhibitors appears to be safe in this patient population and may be considered in patients with clinically significant cardiovascular risk factors. ${ }^{4}$

lago Pinal-Fernandez, M.D., Ph.D.

Andrew L. Mammen, M.D., Ph.D.

National Institutes of Health

Bethesda, MD

iagopf@yahoo.es

No potential conflict of interest relevant to this letter was reported.

1. Barbacki A, Fallavollita SA, Karamchandani J, Hudson M. Immune-mediated necrotizing myopathy and dietary sources of statins. Ann Intern Med 2018;168:893-904.

2. Tiniakou E, Pinal-Fernandez I, Lloyd TE, et al. More severe disease and slower recovery in younger patients with anti-3hydroxy-3-methylglutaryl-coenzyme A reductase-associated autoimmune myopathy. Rheumatology (Oxford) 2017;56:787-94.

3. Mohassel P, Landon-Cardinal O, Foley AR, et al. AntiHMGCR myopathy may resemble limb-girdle muscular dystrophy. Neurol Neuroimmunol Neuroinflamm 2018;6(1):e523.

4. Tiniakou E, Rivera E, Mammen AL, Christopher-Stine L. Use of proprotein convertase subtilisin/kexin type 9 inhibitors in statin-associated immune-mediated necrotizing myopathy: a case series. Arthritis Rheumatol 2019;71:1723-6.

DOI: 10.1056/NEJMc1911058

THE DISCUSSANTS REPLY: Dalakas raises an important point about the relationship between statin use and necrotizing autoimmune myopathy. There is considerable epidemiologic evidence of an association between statin use and necrotizing autoimmune myopathy; however, data to establish statins as causal agents of the illness are lacking. In a large series involving 1947 patients with suspected myopathy who were evaluated at the Johns Hopkins Myositis Center, 104 (5.3\%) were positive for anti-HMGCR autoantibodies. ${ }^{1}$ Of these 104 patients, $75 \%$ had a history of statin use. Widespread use of statins, as seen in the United States, can lead to ascertainment bias, linking a rare myopathy with a commonly used drug class. Nevertheless, in the Johns Hopkins cohort, there was a strong association between antibodies and statin use. However, 25\% of the patients with anti-HMGCR autoantibodies did not have a history of statin use; thus, necrotizing autoimmune myopathy can occur in the absence of statin exposure. As Dalakas suggests, anti-HMGCR autoantibodies may not necessarily be pathogenic, but they could be biomarkers of the immune-mediated process. Although viral illness is a potential trigger, we did not find compelling literature linking viral illness with anti-HMGCR autoantibodies. Although the duration of statin use before anti-HMGCR myopathy is variable, 2 or more years of exposure is frequently reported. Thus, the time course in this patient is consistent with a statin-associated event. ${ }^{2,3}$ We agree that Koch's postulates for causality are not satisfied with regard to the role of statins or HMGCR autoantibodies in causing necrotizing autoimmune myopathy; until there is stronger evidence, it may be better to view the condition as statin-associated rather than statin-induced. We do not agree, however, with rechallenging patients with statins; this perspective was supported in a recent review article stating that all five patients who were rechallenged had adverse effects. ${ }^{4}$ In our opinion, rechallenging a patient with a statin would require conclusive proof that a statin was not implicated in the disorder. Given the very refractory nature of necrotizing autoimmune myopathy, we think alternative cholesterollowering therapy with the use of PCSK9 antibodies or ezetimibe should be the recommended treatment for a patient after the development of a statin-associated anti-HMGCR myopathy.

We thank Pinal-Fernandez and Mammen for their comments. These letters raise important issues in understanding this rare immune-mediated myopathy.

\section{Mason W. Freeman, M.D. \\ Amanda C. Guidon, M.D. \\ Sheila L. Arvikar, M.D.

\author{
Massachusetts General Hospital \\ Boston, MA
}

Since publication of their article, the authors report no further potential conflict of interest.

1. Tiniakou E, Pinal-Fernandez I, Lloyd TE, et al. More severe disease and slower recovery in younger patients with anti-3hydroxy-3-methylglutaryl-coenzyme A reductase-associated autoimmune myopathy. Rheumatology (Oxford) 2017;56:787-94.

2. Christopher-Stine L, Casciola-Rosen LA, Hong G, Chung T, Corse AM, Mammen AL. A novel autoantibody recognizing 200-kd and $100-\mathrm{kd}$ proteins is associated with an immune-mediated necrotizing myopathy. Arthritis Rheum 2010;62:2757-66.

3. Ramanathan $S$, Langguth $D$, Hardy TA, et al. Clinical course and treatment of anti-HMGCR antibody-associated necrotizing autoimmune myopathy. Neurol Neuroimmunol Neuroinflamm 2015;2(3):e96.

4. Nazir S, Lohani S, Tachamo N, Poudel D, Donato A. Statinassociated autoimmune myopathy: a systematic review of 100 cases. J Clin Rheumatol 2017;23:149-54.

DOI: 10.1056/NEJMc1911058

Correspondence Copyright (๑) 2019 Massachusetts Medical Society. 